\title{
Aging and sleep
}

\author{
Horton $A^{*}$ \\ Lewis University and Advisory Board Governors State University, Illinois, USA
}

\begin{abstract}
This paper presents therapeutic methods for neural repair of implicit traits and temperamental characteristics of three personality diagnoses in the DSM V in relation to sleep deprivation. It also extends the understanding of personality development to multicultural factors Health effects of sleep deprivation are also presented.
\end{abstract}

\section{Introduction}

African Americans with sleep apnea and insomnia are rarely diagnosed with either problem, even when the severity of the two sleep disorders are likely to affect their health. This is according to recent research. "African Americans experience a disproportionate burden of numerous health problems, including obesity, diabetes, hypertension, and cardiovascular disease, all of which have been shown to be associated with sleep," says lead study author Dayna A. Johnson, $\mathrm{PhD}, \mathrm{MPH}, \mathrm{MS}$, MSW, a postdoctoral research fellow at Brigham and Women's Hospital and Harvard Medical School, in a release. "It seems plausible that sleep apnea and insomnia are important risk factors contributing to these health disparities." Here are some ways a lack of sleep can affect your body and mind:

The immune system becomes impaired, causing you to get sick more easily. Weight gain is more likely, due to increased levels of ghrelin, the hormone that stimulates appetite. The risk of diabetes is higher because sleep helps the body process carbohydrates. Blood pressure is raised, as are levels of chemical related to inflammation. Depression and anxiety are more common for the suffering a chronic sleep debt.

Johnson and her colleagues studied data of 825 African Americans who underwent a sleep study as part of the Jackson (Miss) Heart Study, which is funded by the National Institutes of Health and is the largest single-site prospective investigation of cardiovascular disease in African Americans undertaken. The average age of those undergoing the home sleep study was 63 years, and two-thirds of the participants were women.

The researchers defined sleep apnea based on the apnea-hypopnea index (AHI). An AHI > 5 was considered mild; an AHI > 15, moderate; and an AHI $>30$, severe. The researchers used the Women's Health Initiative (WHI) Insomnia Rating Scale to define insomnia. Participants with a score $>10$ were considered to have insomnia. Participants were asked if a physician had told them that they suffered from either of the disorders.

The study found that three of every four participants had sleep apnea: $38.4 \%$ had mild sleep apnea; $21.3 \%$ had moderate sleep apnea; and $15.8 \%$ had severe sleep apnea. But only $2.1 \%$ of those with sleep apnea reported that a physician diagnosed the condition. Higher body mass index, hypertension, diabetes, being male, and being older were all associated with sleep apnea and its severity.
The study also found that more than 2 in 10 participants suffered from insomnia. But only $6.7 \%$ of them reported a physician diagnosis. According to Johnson, the prevalence of both sleep apnea and insomnia in the study population was higher than would be expected in the general population of adults of a similar age.

"There is a disturbingly high prevalence of undiagnosed sleep disorders in our study population of African Americans," she says. "It is important to investigate the reasons for this high prevalence as well as investigate interventions targeted at increasing awareness and screening for sleep disorders."

Because treating these sleep disorders "could drastically improve quality of life and reduce the burden of subsequent adverse health outcomes," Johnson adds, clinicians need to identify patients at risk of these sleep disorders and encourage them to undergo sleep studies. In addition, although public awareness of sleep problems is growing, efforts targeting the most at-risk populations may be warranted. Risk factors that may be related to mental health are presented below (Figure 1).

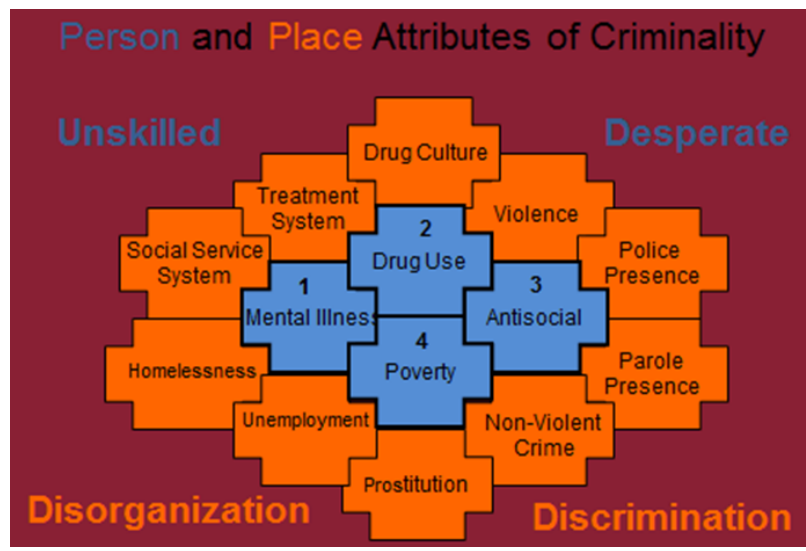

Figure 1. Risk factors that may be related to mental health

Correspondence to: Arthur Horton, PH.D, LCSW and MHS, Lewis University and Advisory Board Governors State University, Illinois, USA, E-mail: ahorton5201@gmail.com

Received: October 11, 2017; Accepted: November 20, 2017; Published: November 25, 2017 
What's going on here? That's harder to determine. One thing that is known is that it's not just socioeconomic factors. While the race gap gets smaller when you take income into account, it doesn't go away, and while living in a safe, quiet neighborhood (which is likely more expensive) can help you sleep better, that doesn't explain the problem entirely, either. Another potential cause is higher levels of stress and worry (minorities are likelier to deal with discrimination in their daily lives). Intrestingly, there's also a difference in how sleep habits are taught to children of different races. Caucasian children are likelier to have strict bedtimes than African American or Hispanic children. By missing out on learning sleep habits as a kid, it can be harder to create them from scratch as an adult. This factor itself maybe correlated to mental health of the associated parent(s).

\section{Narcissistic personality disorder and problems in sleeping}

There is a pattern doing REM sleep processes pertaining to dreaming become intense and disturbing to the person affected by it. The quality of the dreaming is extremely intense with sequencing as if one is in a drama. The dreamer at some point experiences the end of the dream scenario as a victim in the drama, if you will. I argue that a person in real life in severe cases of the type of dreaming is burden by high levels of anxiety combined with a personality disorder.

Anxiety and NPD, the possible treatment: Diminish the intensity of harm avoidance which manifest in theme-mastic fashion in content of a particular dreaming experience. The person, whatever the nature of the dream as drama with an outcome, is the object, the victim.

1. Teach appropriate assertiveness in real life context(s)

2. Worry management strategies

3. Energy therapies and self-soothing techniques

4. Dispute irrational fears of humiliation

5. Resolve childhood humiliations

\section{Depression and NPD, possible treatment:}

1. Increase client's sense of self-agency (efficacy)

2. Accept responsibility for vicious circles (acting-out and/or acting in behavior) of grandiosity and loss

3. Battle grandiosity by increasing achievement

4. Improving awareness of and attunement to others

5. Mindfulness techniques and cost-benefit analysis

\section{Interpersonal Relationship and NPD:}

1. Using desire for affiliation

2. Reframe indifference to the others and

3. Motivate connection with dialectical constructs (relevant thesis vs. antithesis imaging)

4. Genuine contributions: The path to legitimate self-worth

\section{Obsessive-compulsive personality disorders and problems sleeping}

Some individuals as they engage in dream activity during REM sleep phase manifest in the dream pursuit of the object of interest/ pleasure most dreaded or prohibited by the super ego. According to Freud "Even punishment -dreams are wish-fulfillments, but they do not fulfill the wishes of the instinctual impulses, but those of the censuring and punishing function of the mind...Every dream is an attempt to put aside a disturbance of sleep by means of a wish-fulfillment. The dream is thus the guardian of sleep. This attempt can be more or less completely successful, it can also fell-in which case the sleeper wakes up, apparently aroused by the dream itself (Freud) [1,2].

There is a pattern doing REM sleep processes pertaining to dreaming become intense and disturbing to the person affected by it. The quality of the dreaming is extremely intense with sequencing as if one is in a drama. The dreamer at some point experiences the end of the dream scenario as "offender /libertine" or otherwise liberated in the drama, if you will. I argue that a person in real life in severe cases of the type of dreaming is burden by high levels of anxiety combined with a personality disorder.

\section{Anxiety and OCPD}

1. Breaking the rule of harm avoidance

2. Identify the conflict with inner values

3. Cognitive Behavioral Therapy (CBT) to change worry and ruminations

4. Real self-focusing techniques to find feelings

5. Discharging anger- one underlying trigger of anxiety

6. Learning to tolerate anxiety of making mistakes

7. Breaking free from the "technology slavery"

\section{Depression and OCPD:}

1. Increase positive agency

2. Change (reverse) derogatory self -talk

3. Interrupt and dispute compulsive behavior

4. Prescribe fun!!

\section{Interpersonal relationship and OCPD:}

1. Address affiliation and anger issues

2. Mindfulness practices to increase

3. Attunement practices to increase

4. "I" statement and negotiation skills

5. Deflate resistance to increase self/other honesty

6. Systems therapy strategies

7. Eliminate passive aggression

Borderline personality disorder: The quest for connection: There is a pattern doing REM sleep processes pertaining to dreaming become intense and disturbing to the person affected by it. The quality of the dreaming is extremely intense with sequencing as if one is in a drama. The dreamer at some point experiences the end of the dream scenario as "abandoned" in the drama, if you will. I argue that a person in real life in severe cases of the type of dreaming is burden by high levels of anxiety combined with a personality disorder. 


\section{Anxiety and BPD}

1. The forgetfulness of harm avoidance must be addressed

2. Fill in skills deficits: Teach and practice conflict

3. resolution skills

4. Ground techniques to increase emotional stability

5. Journaling techniques

\section{Depression and BPD}

1. The forgetfulness of agency

2. Interrupt self- injurious behavior

3. EMDR practices to loosen the

4. grip of the past

5. Minimize catastrophic rumination with CBT

\section{Interpersonal Relationships}

1. Craving affiliation and its destructive impact

2. Improve therapeutic relationships

3. Relationship histories

4. Practice assertiveness

\section{Personality development and multicuralism}

Two levels of socio-cultural context contribute to diversity United States. The first, cultural transition, has two temporal dimensions: historical/generational sequences (cultural evolution), and immigration/acculturation. Historical/generational sequences and immigration/acculturation patterns evolve over time, as a result of changing ideologies or circumstances that influence the second level of socio-cultural contexts: economics, education, ethnicity, religion, gender, age, race, minority/majority status, and regional background.

To amplify on multiculturalism in relation to material presented in prior sections I focus on multiculturalism as it pertains to economics. Economics is a socio-cultural context that has a dramatic impact on everyday life. In this context, distinctions (say among the lifestyles of the poor, the middle class, and the very rich) typically have greater impacts than differences in other contexts. There are more similarities between the poor in Chicago and the poor in other parts of the world than between the poor and the rich in Chicago, New York or Los Angeles. Working-class families report experiencing the greatest burden at times of economic change (whether in a recession, or in an inflationary, robust economic revival). These families also experience a sense of disenfranchisement because they frequently do not fit the requirements for supportive social programs. Middle class families experience themselves as being overtaxed and underserved. At the same time, their high degree of conformity to the consumer ethic of our society ends up constraining the quality of their lives.

The economic context is embedded in a political context, and the poor are increasingly losing out. Of the 33 million poor people in this country, 13 million are children and 500,000 of those children are homeless. Edelman (1992) examines the disturbing trends emerging with poor families in this country.

According to Edelman, "Young families of all races, on whom we can count on to raise healthy children for America's future, are in extraordinary trouble [3]. They have suffered since the early 1970s a frightening cycle of plummeting earnings, a now doubling of birth rates among unmarried women, increasing numbers of single-parent families, falling incomes -- the median income of young families with children fell by 26 percent between 1973 and 1985 -- and skyrocketing poverty rates. Forty percent of all children in families with a' household head under 30 are poor. While many middle-class youths and young families see the future as a choice between a house and a child, many undereducated, jobless, poor youths and young adults trapped in the innercity war zones see the future as a choice between prison or death at the hands of gangs and drug dealers".

Most of these children have parents who work, but low wages and unstable employment leave their families struggling to make ends meet. Poverty can impede children's ability to learn and contribute to social, emotional, and behavioral problems. Poverty also can contribute to poor health and mental health. Risks are greatest for children who experience poverty when they are young and/or experience deep and persistent poverty.

Research is clear that poverty is the single greatest threat to children's well-being. But effective public policies - to make work pay for low-income parents and to provide high-quality early care and learning experiences for their children - can make a difference. Investments in the most vulnerable children are also critical. (National Center for Children in Poverty, January 2013)

\section{Baby boomers as the old people and generational conflict, "the new normal"}

The pattern of ongoing redefinition of beliefs, which unfold during Cultural Revolution and defines the generational sequence, has a spiral pattern [4]. As the Mayans did, one can conceptualize temporal patterns as cycling simultaneously backwards and forward: people draw on experiences from the past, considering the way they fit the present, and use them to plan for the future. This view allows us to value all temporal positions -- those that maintain stability, and those that are in the process of transformation.

Generational differences are certainly a major source of diversity in this country. The everyday impact of generational change and differentiation is more visible now than ever before, because of rapid dissemination of information propelled by technological advances. The media, particularly television and the internet, have a great impact on how different individuals and sub cultures within a society perceive one another. The media also inform us about our own cultural revolution. These historical/generational sequences evolve over time, through consensus about and individual participation in creation of predominant beliefs for each generation. Some of these sequences can be traced through decades, others, through generations [4].

I will briefly summarize some of those themes, beginning with the "Gray Flannel Generation (1950s) and ending with the so-called "X" Generation but now the emergence of "millennial" (2000s). The former group's priorities were working hard, buying a house in the suburbs, marrying young, and have children early. This theme brought about a counter-cultural challenge that involved gender roles and expectations.

Hugh Hefner and Playboy Magazine and Larry Flint expressed another form of dissidence, validating men's sexual needs while devaluing marriage. The Beat Generation emerged objecting to both marriage and work and supporting machismo [5].

Doing one's own thing and taking care of one's own growth becomes paramount. During this historical/generational sequence 
almost every belief previously held in this society was challenged, bringing to the fore a series of social issues; civil rights, women's rights, the antiwar movement, and the hippie generation. This group emphasized androgyny and challenged consumerism, introducing an era of hedonism and drug consumption. Inevitably the pendulum swung, once more, back to a generation (including baby boomers) that embodied materialism and consumerism. A male liberation movement was spawned in reaction to the feminist movement. This time also was the beginning of a movement toward legitimizing gay rights, which is still going on. The decade, the 1980s, saw the women's movement struggling with the Equal Rights Amendment and polarization around abortion and a woman's right to control the reproduction process and demanding consequences and social stigmatization of sexual harassment contributed by males onto women [6].

As we enter the 2000s there are clear historical challenges ahead for this society. Strauss $[6,7]$ argue that the so-called baby bust generation (those born between 1961 and 1981) will be left with the "dirty work" of fixing inherited problems that other generation -- the ones they see as selfish baby boomers and greedy seniors -- lack the vision and political courage to resolve. One of the things that grates this latest generation is the societal hegemony of the baby boomers, who now have one of their own as president. It is an article of faith that this dominance is caused in great measure by the sheer size of the baby boom cohort (those born between 1946 and 1961). Another factor that motivates the baby busters is their dread that the American Dream is over, at least for them.

They fear they are likely to be the first generation to fail to match their parents' economic success. In the economic growth decade between 1980 and 1990, the median income of Americans under age 25 declined by 10.8 percent. For all others, however, income grew by 6.5 percent. Some experts foresee a breach of the social contract that has provided for social insurance programs for the elderly in this society. Young people see the workplace rigged against them. They will pay a higher percentage of their income to social security taxes than any other generation before them, but less than 30 percent expect that they will even draw out of social security what they put in.

Most of all post-boomers -- including the emerging yet ill- defined "X" generation -- make up a survivor population. They are the children of divorce (some 40 percent grew up in broken families) (U.S. News \& World Report, February 22, 1993). According to Strauss [7] many of them as children were allowed to grow up unskilled, unschooled and unwanted in the 1970s and 1980s. Many carry those problems with them. The wealth and income disparity among them will change the focus of class politics -- from raising low-income families to the median to preventing the rootless poor from sinking into a total abyss. And with the advent of the Great Recession things on got worst in terms of generational conflict.

Max Weber, the great sociologist saw the inevitable consequences of the modern mind' disenchantment of the world, saw the unsettling void of relativism left by modernity's dissolution of traditional world view, and saw that modern reason, in which the enlightenment had places for human freedom and progress, yet which could not on its own terms justify universal values to guide human life, had in fact created an iron cage of bureaucratic rationality that permeated every aspect of modern existence [8].

"No one knows who will live in this cage in the future or whether at the end of this tremendous development entirely new prophets will arise, or there will be a great rebirth of old ideas and ideals, or if neither, mechanized petrifaction, embellished with a sort of convulsive self- importance. For the last stage of this cultural development, it might be truly said: "Specialists without spirit, sensualists without heart; this nullity imagines that it has attained a level of civilization never before achieved" [8].

Weber's organizational paradigm which heretofore had been very influential made interesting assumptions but in today's economic, political, and social environment, it no longer holds up. Some of these assumptions are as follows:

a. organizational decisions are made on a rational basis

b. goals help defines boundaries by clarifying who is and who is not working toward "the organizational goal"

c. functional unity, common interests, and consensus is vital in order to maintain survival of the system

d. people have power because of the position they hold in organizations those who have power are easily defined because of the limited number of positions with power

e. humans are non-volitional, sponge-like, malleable organisms who absorb their organizational environments and adapt to them.

The economic reality that this country now confronts has changed the structure, size and dynamics of organizational life. Human longevity is rising but corporate longevity seems to be shrinking. For example, twenty years ago Fortune 500 companies accounted for 20 percent of all American workers, now it's barely 10 percent. The behemoths like Sears, Xerox, General Motors, have been clobbered by huge debt, rising costs, international competition and the stock market's demand for maximum profit. One way to cope is to replace people with machines; another is to move overseas; another is just cut cost by cutting jobs. These big companies have lost nearly 2 million jobs over the last four years. Another 2 million jobs have vanished at smaller firms [9].

The above situation has been countered by small, fast growing firms' latching on to narrow, even faddish, markets from health care to cookies. Those firms are growing faster than the behemoths' decline. Over the same period small businesses have added millions of jobs to the economy. The result is a net increase of 4 million new jobs. The upshot of such economic turmoil is that young workers' disillusionment has grown. Caught in the clash for a few new jobs many have trimmed ambitions. Some have learned one of life's toughest lessons: how to get more out of family, friends, and leisure hours than the job. So, too, older workers worry more about losing their health coverage, about having to work until late in life for financial reasons, and about whether the company will abide by the old rule that respected seniority and loyalty when budget cuts come [10-11].

The emergence of the organization of the new age has forced the individual into a deep quandary, but one which augurs both hope and promise. Bureaucratic structure provided an iron-clad rationality that staked a claim on objective truth.

Today we confront multiple realities. Truth is no longer a theoretical matter but has been transformed in to practice (the antithesis of theory). 'Today we are no longer inclined to say what is or is not. We are inclined to see that either response will have a series of consequences. We compare both series of possible consequences. If one of the series, say the first, is more favorable, then that would be the truth. This has been further exacerbated with the advent of social media. 


\section{Conclusion}

I present a case. This is my struggle and challenges to sleep each and every night. Beyond the usual varieties of anxieties experienced by most American these days and those unique to the African American population I have avoidance going to sleep at night. I have dread for dreaming due to painful content which happens in a random fashion. At best I have trained myself to wake up to disrupt the what call a "bad dream". At best this is done only three times a given night with me feeling rested the following day with an urge to nap about 2:00p.m., at worst despite every effort to return to a sleep state is not achieved but may happen at an awkward time 6:00a.m. As stated previously severity may be determined by personality stability. Experts also caution us about these factors: caffeine, alcohol, tranquilizers, and most Rx sleeping pills and narcotics.

\section{References}

1. Freud S. New Introductory Lectures on Psychoanalysis, chap 1
2. Freud S. An Outline of Psychoanalysis and The Interpretation of Dreams

3. Berry JW, Kalin R, Taylor DM (1977) Multiculturalism and Ethnic Attitudes in Canada, Ottawa: Government of Canada

4. Breulin DC, Schwartz RC, Karrer MB (1992) Metaframeworks, SanFrancisco: JoseyBass

5. Edelman RW (1992) The Measure of Our Success, Boston: Beacon

6. Enrenreich B (1983) The Heart of Man, New York; Anchor Press

7. Freidan, B. The Feminine Mystique, New York: Norton, 1963

8. Howe N, Strauss B (1993) The 13th Generation; Abort, Retry, Ignore, Fail? NewYork: Vantage Books

9. Strent M, Harzard W, Riulin H (1973) Cultural Pluralism in Education: a Mandate for Change, East Norwalk, Conn; Appleton and Lange

10. Weber M. The Protestant Ethic and the Spirit of Capitalism translated by Talcott

11. Parson New York: Charles Scribner's Sons.1958

Copyright: (C2017 Horton A. This is an open-access article distributed under the terms of the Creative Commons Attribution License, which permits unrestricted use, distribution, and reproduction in any medium, provided the original author and source are credited. 